\title{
KAJIAN ASPEK AGROKLIMAT, BIO FISIK DAN AGRONOMIS PENGEMBANGAN INDIKASI GEOFRAFIS JERUK BESAR MERAH PANGKEP KABUPATEN PANGKAJENE KEPULAUAN
}

\section{STUDY OF AGRO CLIMATE, BIOPHYSICAL, AND AGRONOMIC ASPECTS OF THE DEVELOPMENT OF GEOGRAPHIC INDICATIONS OF RED PUMMELO PANGKEP, PANGKAJENE DAN KEPULAUAN REGENCY}

\author{
Dahlia $^{1)}$, Nurmiaty $^{2)}$, Rahmad $^{2)}$, Reta $^{3)}$ \\ 1)Teknologi Pembenihan Ikan, Jurusan Budidaya Perikanan /Politani Pangkep \\ 2) Teknologi Produksi Tanaman Pangan, Jurusan Perkebunan/Politani Pangkep \\ 3)Agroindustri, Pengolahan Hasil Perikanan/Politani Pangkep
}

Korespondensi: rahmadd_rah@yahoo.co.id

\begin{abstract}
ABSTRAK
Jeruk besar merah pangkep merupakan komoditi unggulan Kabupaten Pangkep yang potensial mendapatkan perlindungan hukum dan Indikasi Geografis. Tujuan penelitian ini adalah untuk mengetahui aspek agroklimat, bio fisik dan kimia lahan dan aspek budidaya yang merupakan bagian dalam pengusulan indikasi geografis yang diperlukan. Metode penelitian yang digunakan adalah kombinasi penelitian kuantitatif dan kualitatif yaitu dengan survei lahan dan pengambilan sampel tanah di lapangan serta hasil analisis sampel tanah di laboratorium dan melalui kegiatan Focus Group Discussion (FGD). Data yang dikumpulkan berupa data sekunder dan data primer yang berasal dari pengamatan langsung di lapangan. Hasil penelitian menunjukkan bahwa lokasi pengembangan jeruk yang terdapat di Kecamatan Labakkang, Mar'rang dan Sigeri dari aspek agroklimat, bio fisik lahan sudah sesuai yang syarat tumbuh yang dibutuhkan oleh tanaman jeruk. Kondisi kimia tanah kandungan unsur hara makro Nitrogen, Fosfor dan Kalium masih rendah. Aspek agronomi menunjukkan petani sebagian besar sudah melaksanakan kegiatan pemeliharan tetapi dalam kegiatan panen buah jeruk sebagian besar petani tidak melakukan penjarangan buah dan sortasi buah. Berdasarkan aspek agroklimat, bio fisik dan kimia lahan serta aspek agronomi, tanaman jeruk besar merah Pangkep sudah sesuai untuk dijadikan sebagai Indikasi Geografis.
\end{abstract}

Kata Kunci: Indikasi Geografis, bio fisik lahan, Jeruk besar merah, Pangkajene Kepulauan.

\begin{abstract}
Red Pomelo Pangkep has the potential to get legal protection and Geographical Indications. The agro climate, biophysical, and chemical aspects of the land, as well as cultivation aspects evaluated in this research. Mix method research applied to collect data. The method includes surveys, soil analysis, and Focus Group Discussion (FGD) activities. The land agroclimatic and biophysics aspects meet the growth needs of cultivation red pomelo in Labakkang, Ma'rang, and Sigeri District. Macronutrients of soil, including nitrogen, phosphorus, and Potassium was low levels. Most of the farmers carried out agronomic aspects but harvesting activities. Most of them have not done fruit thinning and fruit sorting. Based on the analyzed aspects, red pomelo Pangkep is suitable to use Geographical Indications.
\end{abstract}

Keywords: Geographical Indications, bio-physical land, red pomelo, Pangkajene Islands. 


\section{PENDAHULUAN}

Kabupaten Pangkep adalah daerah penghasil jeruk pamelo terbesar di Sulawasi Selatan (Rahayu, 2012) yang berkontribusi lebih dari $80 \%$ produksi jeruk di wilayah Provinsi ini (Kementerian Pertanian, 2016). Kontribusi Sulawesi Selatan secara nasional dalam pasokan produksi jeruk pamelo menempati urutan pertama yaitu sebesar $30.76 \%$. Komoditi ini menjadi salah satu produk unggulan di kabupaten Pangkep.

Tanaman jeruk besar banyak dikembangkan di Kabupaten Pangkep yaitu di kecamatan yaitu Labakkang, Ma'rang, dan Segeri (Thamrin, 2014). Kondisi tersebut mengindikasikan bahwa jenis jeruk ini dapat tumbuh dan berkembang dengan baik melalui sistem budidaya tanaman pada area dengan kondisi geografis tertentu. Pengaruh faktor alam yang spesifik, sebagaimana pada tiga wilayah kecamatan di Kabupaten Pangkep tersebut mengindikasikan bahwa produk jeruk pamelo dapat dilindungi dengan Peraturan Pemerintah tentang Indikasi Geografis. Perlindungan tersebut dapat mencegah tindakan-tindakan pemalsuan produk khas daerah.

Permasalahan bagaimana kondisi agroklimat, bio fisik dan kimia lahan dan sistim budidaya tanaman yang dilakukan oleh petani dapat dijadikan sebagai salah satu faktor pendukung di dalam menentukan indikasi georgrafis dari jeruk besar merah Pangkep yang dihasilkan. Sehubungan dengan permasalahan tersebut maka dilakukan penelitian terhadap aspek agroklimat, bio fisik dan kimia lahan dan sistim budidaya tanaman jeruk besar merah pangkep. Hasil penelitian akan digunakan di dalam penyusunan indikasi geografis sebagai salah satu produk unggulan Kabupaten Pangkep dan penjaminan kualitas produk jeruk pamelo Pangkep.

\section{BAHAN DAN METODE}

Lokasi penelitian di lakukan di Kecamatan Labbakkang, Sigeri dan Mar'rang. Letak geografis lokasi penelitian yaitu terletak pada posisi $4^{\circ} 33^{\prime} 21.6^{\prime \prime}$ - 4 $49^{\prime} 8.4^{\prime \prime} "$ Lintang Selatan dan $119^{\circ}$ $28^{\prime} 48^{\prime \prime}$ - $119^{\circ} 41^{\prime} 9.6^{\prime \prime}$ Bujur Timur. Bahan yang digunakan pada penelitian ini adalah peta kecamatan meliputi peta administrasi, peta jenis tanah, peta lereng dan peta penggunaan lahan, serta beberapa jenis bahan kimia untuk identifikasi tanah dan analisis kimia tanah di laboratorium. Alat yang digunakan adalah $\mathrm{pH}$ tancap, bor tanah, Global Positioning System $(G P S)$, sekop, cangkul, alat tulis, printer, kamera digital dan seperangkat laptop yang telah terpasang software Microsoft Office 2019 dan ArcGIS 10.8. dan quesioner untuk mendapatkan 
informasi sistem budidaya tanaman yang dilaksanakan oleh petani. Penelitian ini merupakan penelitian campuran kualitatif dan kuantitatif (mix method) yaitu dengan survey lahan dan pengambilan sampel tanah di lapangan serta hasil analisis sampel tanah di laboratorium dan kegiatan Focus Graoup Discussion (FGD). Data yang dikumpulkan berupa data sekunder dan data primer yang berasal dari pengamatan langsung di lapangan dianalisis secara deksriptif.

\section{HASIL DAN PEMBAHASAN}

\section{A. Kondisi Agroklimat}

Produktivitas dan kualitas tanaman jeruk sangat ditentukan oleh faktor iklim dan lingkungan (Ridhani, 2017). Wilayah Kecamatan Labakkang, Mar'rang dan Sigeri memiliki curah hujan $>2.400 \mathrm{~mm} /$ tahun dan termasuk bulan basah (Tabel 1). Jeruk pamelo membutuhkan temperatur optimum $25-32{ }^{\circ} \mathrm{C}$ dengan curah hujan tahunan optimum sebsar $150 \mathrm{~cm}$ hingga $180 \mathrm{~cm}$ untuk pertumbuhan dan produksi terbaik (Agrifarming, 2021). Tanaman jeruk secara umum membutuhkan curah hujan 1.000-3.000 mm/th (optimum 1.500-2.500 mm/th). Bulan kering (curah hujan kurang dari $60 \mathrm{~mm} / \mathrm{bulan}$ ) 2-6 bulan (optimum 3-4 bulan) dan Suhu 13$35^{\circ} \mathrm{C}$ (optimum $22-23^{\circ} \mathrm{C}$ ) (Endarto \& Martini, 2016). Dengan demikian, kondisi agroklimat wilayah pengembangan mengindikasikan jeruk besar merah Pangkep sangat cocok untuk budidaya tanaman tersebut.

Tabel 1. Luas area menurut klasifikasi curah hujan dan wilayah kecamatan pengembangan jeruk besar merah Pangkep.

\begin{tabular}{|l|c|c|c|}
\hline \multirow{2}{*}{ Klasifikasi } & \multicolumn{3}{c|}{ Luas Area (ha) } \\
\cline { 2 - 4 } & Labakkang & Mar'rang & Sigeri \\
\hline Bulan kering $(\mathrm{CH}<1.200 \mathrm{~mm} /$ tahun$)$ & 0 & 0 & 0 \\
\hline $\begin{array}{l}\text { Bulan lembab }(\mathrm{CH} 1.200-2.400 \\
\text { mm/tahun) }\end{array}$ & 0 & 0 & 0 \\
\hline Bulan basah $(\mathrm{CH}>2.400 \mathrm{~mm} /$ tahun $)$ & $10,182.79$ & $8,864.73$ & $6,923.69$ \\
\hline
\end{tabular}

\section{B. Kondisi Bio Fisik Lahan}

Lahan penanaman jeruk di Kecamatan Labakkang, Mar'rang dan Sigeri memiliki kemiringan 0-8\%, dengan ketinggian 0-100 mdpl (Tabel 2). Jenis tanah yang di dominasi oleh jenis tanah aluvial, Grumusol dan mediteran merah, kuning dan litosol dengan kedalaman $>150 \mathrm{~cm}$. Kandungan batuan berkisar 0-15\% dan lebih banyak lahan yang memiliki kandungan batu < 3\%. Kandungan partikel dan tekstur tanah di dominasi oleh wilayah yang memiliki kandungan lempung sampai lempung berdebu (Tabel 3). Kesesuaian lahan adalah tingkat kecocokan lahan 
untuk penggunaan tertentu (Rosmaiti et al., 2019). kesesuaian lahan aktual dapat dijadikan sebagai pedoman dalam upaya pengelolaan lahan untuk dapat mencapai produktifitas normal (Hartono et al., 2018). Syarat tumbuh tanaman jeruk pamelo ditanam pada ketinggian tempat 0-400 mdpl. Solum dalam (optimum >1m), tidak ada lapisan kedap air; tekstur berpasir hingga lempung berpasir; drainase dan airasi (Endarto \& Martini, 2016).

Tabel 2. Luas area menurut kondisi fisik lahan dan wilayah kecamatan pengembangan jeruk besar merah Pangkep.

\begin{tabular}{|c|c|c|c|}
\hline \multirow{2}{*}{ Parameter Fisik Lahan } & \multicolumn{3}{|c|}{ Luas Area (ha) } \\
\hline & Labakkang & Mar'rang & Sigeri \\
\hline \multicolumn{4}{|l|}{ Elevasi } \\
\hline Datar $(0-3 \%)$ & $6.225,825$ & $4.666,534$ & $3.661,514$ \\
\hline Agak Datar (3-8\%) & $3.535,669$ & $3.467,026$ & $1.165,496$ \\
\hline Bergelombang (8-15\%) & 347,375 & 311,404 & $1.029,596$ \\
\hline Bergumuk (15-25\%) & 37,922 & 270,308 & 724,352 \\
\hline Berbukit $(25-40 \%)$ & 0 & 149,424 & 297,354 \\
\hline Bergunung dan curam $(>40 \%)$ & 0 & 0 & 45,375 \\
\hline \multicolumn{4}{|l|}{ Ketinggian (mdpl ) } \\
\hline $0-100 \mathrm{mdpl}$ & 10158.6 & 8868.6 & 6762.7 \\
\hline $100-200 \mathrm{mdpl}$ & 0 & 41.7 & 209.1 \\
\hline 200-300 mdpl & 0 & 3.1 & 27.7 \\
\hline $300-400 \mathrm{mdpl}$ & 0 & 0 & 2.4 \\
\hline $400 \mathrm{mdpl}$ & 0 & 0 & 0 \\
\hline \multicolumn{4}{|l|}{ Jenis Tanah } \\
\hline Aluvial Hodromorf,Glei Humus & 2475.17 & 576.72 & 0 \\
\hline Aluvial,Grumusol & 3796.93 & 4358.95 & 2847.27 \\
\hline Mediteran Merah Kuning, Litosol, & 3368.15 & 2887.09 & 36.43 \\
\hline $\begin{array}{l}\text { Mediteran Merah Kuning, } \\
\text { Litosol/Regosol }\end{array}$ & 243.34 & 905.04 & 4089.2 \\
\hline \multicolumn{4}{|l|}{ KedalamanTanah } \\
\hline Sangat Dangkal $(<25 \mathrm{~cm})$ & 0 & 0 & 0 \\
\hline Dangkal $(26-50 \mathrm{~cm})$ & 0 & 0 & 775,476 \\
\hline Sedang $(51-75 \mathrm{~cm})$ & 498,433 & 213,061 & 328,568 \\
\hline Agak Dalam $(76-100 \mathrm{~cm})$ & 0 & 0 & 0 \\
\hline Dalam $(101-150 \mathrm{~cm})$ & 262,850 & 497,296 & $2.178,588$ \\
\hline Sangat Dalam $(>150 \mathrm{~cm})$ & $9.352,490$ & $8.148,851$ & $3.636,986$ \\
\hline \multicolumn{4}{|l|}{ Kandungan Batuan } \\
\hline Tidak Berbatu $(<3 \%)$ & $7.071,095$ & $4.992,942$ & $6.465,360$ \\
\hline Berbatu $(11-15 \%)$ & $3.042,678$ & $3.866,266$ & 454,258 \\
\hline Sangat Berbatu (16-25\%) & 0 & 0 & 0 \\
\hline Amat Sangat Berbatu (26-50\%) & 0 & 0 & 0 \\
\hline Lahan Berbatu (> $50 \%)$ & 0 & 0 & 0 \\
\hline Partikel dan Tekstur Tanah & & & \\
\hline
\end{tabular}




\begin{tabular}{|l|c|c|c|}
\hline \multirow{2}{*}{ Parameter Fisik Lahan } & \multicolumn{3}{|c|}{ Luas Area (ha) } \\
\cline { 2 - 4 } & Labakkang & Mar'rang & Sigeri \\
\hline Liat & 0 & 0 & 372,682 \\
\hline Lempung & $6.465,772$ & $3.952,209$ & $3.493,410$ \\
\hline Lempung berliat & $3.042,678$ & $4.498,521$ & 767,122 \\
\hline Lempung Berdebu & 605,323 & 408,478 & $2.286,404$ \\
\hline Lempung Berpasir & 0 & 0 & 0 \\
\hline
\end{tabular}

\section{Kandungan Kimia Tanah}

Kondisi pH di wilayah Kecamatan Labakkang, Mar'rang dan Sigeri yaitu memiliki pH tanah netral (6-7.0). Sebagian lahan di tiga kecamatan penanaman jeruk berada pada kisaran pH 5.5 - 6.5. Wilayah di tiga kecamatan pada umumnya memiliki kandungan C-Organik tanah yang rendah yaitu berada pada kisarn 0-2,0 dan Kapasitas Tukar Kation berada pada tingkat rendah sampai sedang (5-25).

Kandungan unsur hara di lahan lokasi penelitian memiliki kandungan hara nitrogen mulai sangat rendah sampai rendah. Sebagian besar lahan memiliki kandungan fosofor yang tinggi dan sangat tinggi walapun sebagian lahan ada yang kandungan fosfornya sangat rendah sedangkan kandungan unsur hara kalium hanya pada daerah kecamatan Mar'rang dan Sigeri yang memiliki kandungan kalium sangat tinggi > 1 sedangkan lahan di tiga kecamatan sebagian besar memiliki kandungan kalium mulai sangat rendah sampai rendah.

Kondisi unsur hara tanah di lokasi penelitian pada umumnya masih rendah hal ini disebabkan karena selama ini petani melakukan pemupukan belum melakukan sesuai dosis pemupukan yang optimal. Petani hanya berdasarkan pengalaman dan mengikuti kebiasaan sendiri (Juliati, 2010). Kebutuhan unsur hara bagi tanaman seharusnya disesuaikan dengan kondisi dan fase pertumbuhan tanaman (Menzel et al., 1992).

Tabel 3. Luas area menurut parameter kimia tanah dan wilayah kecamatan pengembangan tanaman jeruk besar merah Pangkep.

\begin{tabular}{|c|c|c|c|}
\hline \multirow{2}{*}{ Parameter Kimia Tanah } & \multicolumn{3}{|c|}{ Luas Area (ha) } \\
\cline { 2 - 4 } 1. Kemasaman (pH) tanah & Labakkang & Mar'rang & Sigeri \\
\hline$\bullet$ Agak Masam Atas $(5,5-6,0)$ & & & \\
\hline$\bullet$ Agak Masam Bawah $(6,0-6,5)$ & 3.42 & 4.28 & 5.41 \\
\hline • Netral Bawah (6,5-7,0) & 0.00 & 3.95 & 1.20 \\
\hline 2. C-organik tanah & & 6.32 & 3.22 \\
\hline$\bullet$ Sangat Rendah (<1,0) & $6.870,753$ & $4.045,304$ & $3.782,884$ \\
\hline • Rendah $(1,0-2,0)$ & $3.276,038$ & $4.819,392$ & $3.140,803$ \\
\hline$\bullet$ Sedang $(2,01-3,0)$ & 0 & 0 & 0 \\
\hline
\end{tabular}




\begin{tabular}{|c|c|c|c|}
\hline \multirow{2}{*}{ Parameter Kimia Tanah } & \multicolumn{3}{|c|}{ Luas Area (ha) } \\
\hline & Labakkang & Mar'rang & Sigeri \\
\hline \multicolumn{4}{|l|}{ 3. Kapasitas Tukar Kation } \\
\hline - Sangat Rendah $(<5)$ & 0 & 0 & 0 \\
\hline - Rendah (5-17), & $9.913,433$ & 8.543 .831 & $4.589,259$ \\
\hline - Sedang (18-25) & 233,358 & 320,865 & $1.959,705$ \\
\hline - Tinggi (26-40). & 0 & 0 & 374,723 \\
\hline \multicolumn{4}{|l|}{ 4. Nitrogen-Total Tanah } \\
\hline - Sangat Rendah & $6.498,788$ & $3.957,690$ & $3.454,316$ \\
\hline - Rendah & $3.648,003$ & $4.907,006$ & $3.469,371$ \\
\hline \multicolumn{4}{|l|}{ 5. Kandungan Fosfor } \\
\hline - Sangat Rendah $(<4,4)$ & 371,965 & 87,614 & 367,474 \\
\hline - Rendah $(4,4-7,04)$ & 0 & 0 & 0 \\
\hline - Sedang $(7,05-11,44)$ & 0 & 0 & 0 \\
\hline - Tinggi $(11,45-15,4)$ & $3.042,680$ & $3.866,267$ & 454,261 \\
\hline - Sangat Tinggi $(>15,4)$ & $6.732,146$ & $4.910,815$ & $6.101,651$ \\
\hline \multicolumn{4}{|l|}{ 6. Kandungan Kalium } \\
\hline - Sangat Rendah $(<0,1)$ & $3.042,680$ & $3.866,267$ & 493,468 \\
\hline - Rendah $(0,1-0,3)$ & $7.104,111$ & $4.366,169$ & $6.117,312$ \\
\hline - Sedang $(0,4-0,6)$ & 0 & 0 & 0 \\
\hline - Tinggi $(0,7-1)$ & 0 & 0 & 0 \\
\hline - Sangat Tinggi $(>1)$ & 0 & 632,260 & 312,907 \\
\hline
\end{tabular}

\section{Keadaan Budidaya Tanaman}

\section{Pola Tanam}

Penanaman jeruk di lokasi penelitian diterapkan pola monokultur sebesar $44.44 \%$, tumpangsari sebesar 66.56\% (Gambar 1A). Jenis tanaman yang ditumpangsarikan dengan tanaman jeruk antara lain yaitu tanaman pisang, kelapa dan jenis tanaman lainnya. Kombinasi penanaman jenis jeruk di dalam satu lahan paling banyak yaitu kombinasi jenis jeruk putih dan merah yaitu sebesar $70 \%$ dan sisanya hanya menanam salah satu jenis jeruk putih atau merah masing-masing sebesar 10\% dan 20\% (Gambar 1B). Banyak petani yang melakukan sistem penanaman yang mengkombinasikan ini disebabkan karena kedua jenis jeruk memiliki konsumen yang berbeda. Ada konsumen yang menyukai jeruk putih dan ada yang suka dengan jeruk merah. 
Pola tanam pada tanaman jeruk dapat dikembangkan baik melalui sistem pola tanam monokultur dan pola tanam polikultur (Vitriyatul, 2012). Tumpangsari pada tanaman jeruk dapat dihasilkan hasil secara maksimal pada suatu lahan per musim (Rehman et al., 2014). Hasil penelitian pola tanam tumpangsari kedelai pada jeruk menghasilkan produktivitas jeruk yang tinggi dibandingkan dengan monokultur (Srivastava et al., 2007). Hal ini disebabkan tanaman tumpangsari tersebut (kedelai) menjadikan ketersediaan hara di dalam tanah menjadi tinggi (Knörzer et al., 2009).
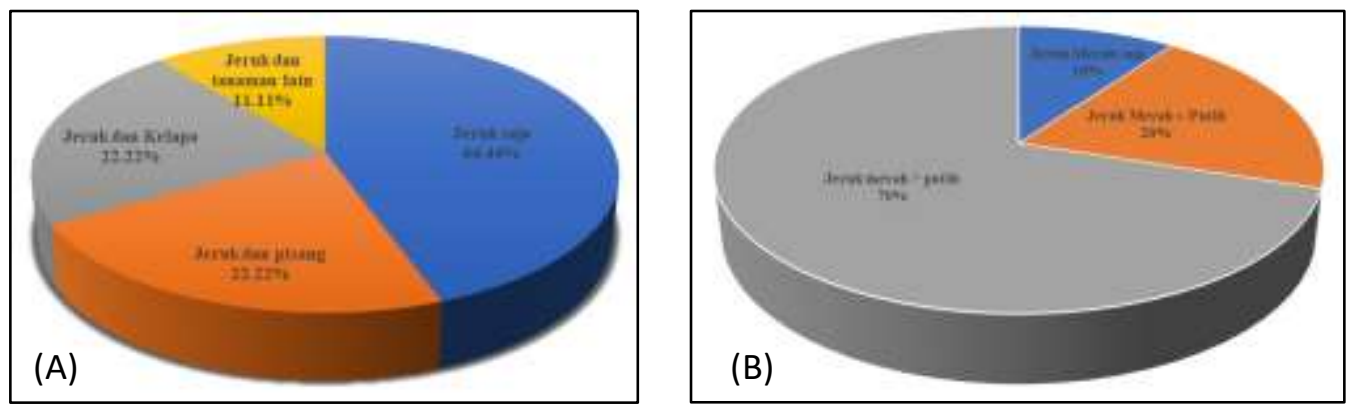

Gambar 1. Persentase petani menurut pola tanam (A) dan jenis jeruk (B) yang dikembangkan di wilayah Indikasi Geografis.

\section{Pemeliharaan Tanaman}

Pada umumnya kegiatan pemeliharaan tanaman jeruk di lokasi penelitian telah dilakukan oleh petani yaitu sebanyak 77,80\% dan tidak melakukan pemeliharaan sebanyak 22,20\% (Gambar 2A). Kegiatan pemeliharaan tanaman yang dilakukan oleh petani meliputi kegiatan pemangkasan, pemupukan dan pengendalian hama dan penyakit yang hampir semuanya dilakukan yaitu semua masuk pada kategori kegiatan pemeliharaan yang tidak sering sampai pemeliharaan sering yang persentasenya sangat bervariasi dari kegiatan pemeliharaan yang dilakukan (Gambar 2B - 2D). Menurut Sutopo (2014), keberhasilan budidaya jeruk juga dipengaruhi oleh pemilihan lokasi, penyiapan lahan dan pemeliharaan tanaman.

\section{Panen}

Petani jeruk yang melakukan kegiatan penjarangan buah tidak rutin sebanyak $40 \%$, rutin melakukan penjarangan sebanyak 20\% dan yang tidak melakukan sama sekali yaitu sebanyak 40\% (Gambar 3A). Sementara petani yang memetik buah jeruk yang masih hijau sebanyak $40 \%$ dan yang tidak memetik buah hijau sebanyak 60\% (Gambar 3 B). Petani jeruk sebagian besar tidak melakukan sortasi buah yaitu sebanyak 78.00\% sedangkan yang melakukan sortasi sebanyak 22.00\% (Gambar 3C). Petani jeruk yang tidak melakukan penjarangan lebih mementingkan jumlah buah yang banyak disebabkan karena selama ini buah yang besar dan buah yang kecil tetap terjual, sementara yang melakukan penjarangan lebih menginginkan buah jeruk yang lebih besar karena harganya jauh lebih tinggi. Penjarangan 
pada tanaman jeruk dilakukan pada pohon yang mempunyai buah lebat dengan tujuan untuk memperbaiki kualitas buah dan kestabilan pada musim panen berikutnya (Lesmana, 2009).
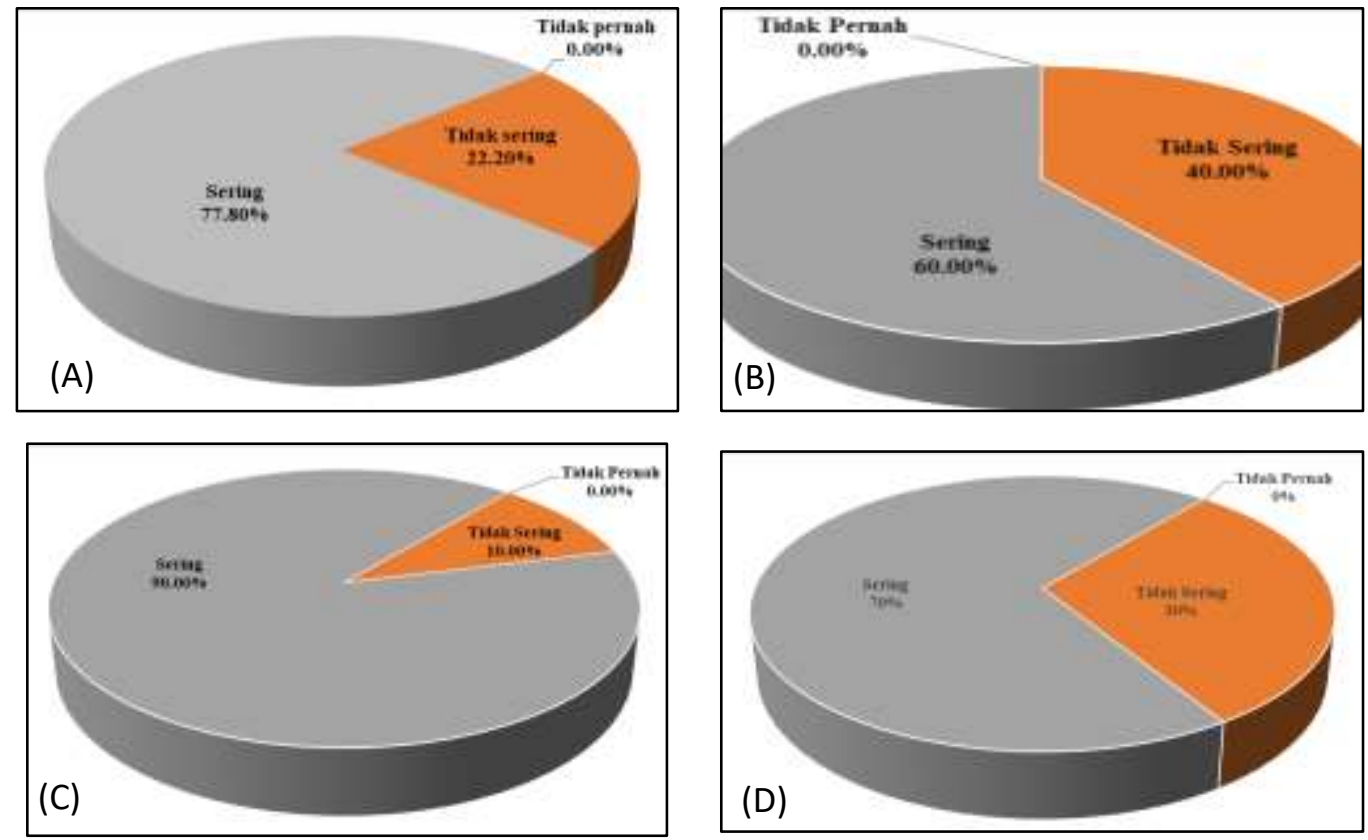

Gambar 2. Persentase petani yang melakukan perawatan (A), pemangkasan (B), pemupukan (C), dan pengendalian hama dan penyakit (D) tanaman jeruk di wilayah pengembangan indikasi geografis jeruk besar merah Pangkep

Banyak faktor yang menyebabkan petani melakukan panen saat kulit buahnya masih hijau salah satunya karena cepat mau menjual buah jeruk yang dihasilkan dan kegiatan sortasi buah tidak dilakukan disebabkan karena pada umunya buah jeruk dibeli oleh pembeli sistem borongan

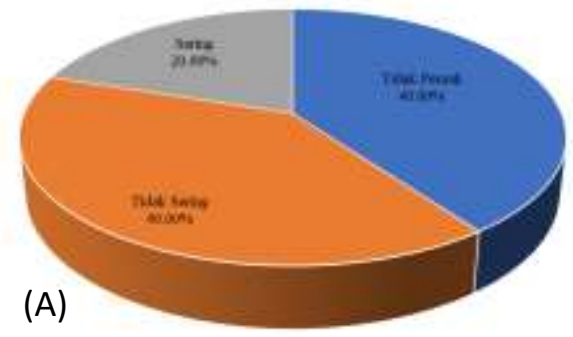

(B)

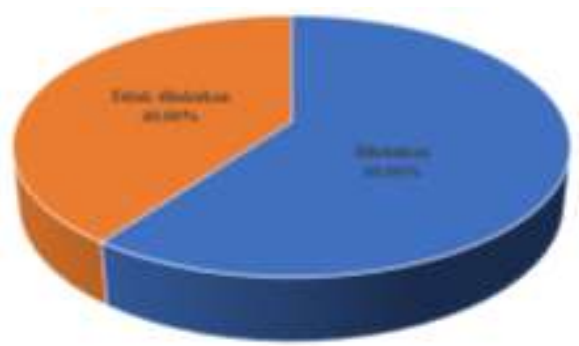

(C)

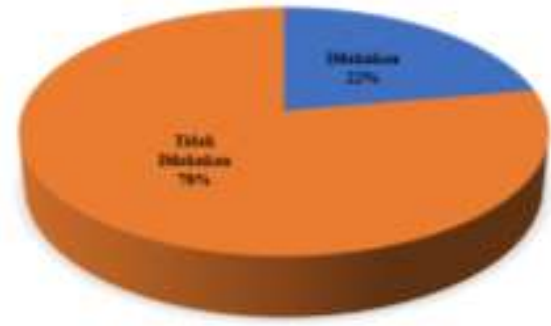

Gambar 3. Persentase petani menurut aktifitas penjarangan buah, panen buah hijau, dan sortasi buah saat panen jeruk besar merah Pangkep di wilayah Indikasi Geografis 


\section{KESIMPULAN}

Berdasarkan hasil penelitian yang dilakukan dapat disimpulan sebagai berikut:

1. Berdasarkan aspek agroklimat yang terdapat pada lokasi pengembangan jeruk besar di Kecamatan Labakkang, Mar'rang dan Sigeri sudah sesuai untuk mendukung pertumbuhan dan produksi tanaman jeruk besar.

2. Pengembangan jeruk merah besar yang dilakukan oleh petani menerapkan sistem pola monokultur dan tumpangsari.

3. Petani di Kecamatan Labakkang, Mar'rang dan Sigeri sudah menerapkan aspek pemeliharaan tanaman yang sudah memadai.

4. Petani di Kecamatan Labakkang, Mar'rang dan Sigeri sudah melakukan kegiatan peningkatan mutu jeruk melalui kegiatan panen.

\section{UCAPAN TERIMA KASIH}

Ucapan terima kasih kepada Politeknik Pertanian Negeri Pangkep atas berbagai fasilitas untuk pelaksanaan kegiatan ini, serta Pemerintah Daerah Kabupaten Pangkep yang telah bekerjasama di dalam mendanai kegiatan penelitian untuk pengembangan Indikasi Geografis ini.

\section{DAFTAR PUSTAKA}

AGRIFARMING. (2021). Rosemary Cultivation Information Guide. https://www.agrifarming.in/ pomelo-cultivation

Endarto, O., \& Martini, E. (2016). Pedoman Budi Daya Jeruk Sehat. In A. L. Gael (Ed.), Balai Penelitian Tanaman Jeruk Dan Buah Subtropika (Balitjestro). World Agroforestry Centre.

Hartono, B., Rauf, A., Elfiati, D., Harahap, F. S., \& Sidabuke, S. H. (2018). Evaluasi Kesesuaian Lahan Pertanian Pada Areal Penggunaan Lain Untuk Tanaman Kopi Arabika(Coffea Arabica L.) Di Kecamatan Salak Kabupaten Pak-Pak Bharat. Jurnal Solum, 15(2), 66. https://doi.org/10.25077/jsolum.15.2.66-74.2018

Juliati, S. (2010). Penentuan Indeks Kebutuhan Hara Makro Pada Tanaman Mangga Dengan Metode Diagnosis and Recommendation Integrated System. Jurnal Hortikultura, 20(2), 120-129. https://doi.org/10.21082/jhort.v20n2.2010.p

Kementerian Pertanian. (2016). Outlook Komoditas Pertanian Sub Sektor Hortikultura: Jeruk. Pusat Data dan Sistem Informasi Pertanian Kementerian Pertanian.

Knörzer, H., Graeff-Hönninger, S., Guo, B., Wang, P., \& Claupein, W. (2009). The Rediscovery of Intercropping in China: A Traditional Cropping System for Future Chinese Agriculture - A Review. In Climate Change, Intercropping, Pest Control and 
Beneficial Microorganisms (pp. 13-44). https://doi.org/10.1007/978-90-481-2716-0_3

Lesmana, D. (2009). Analisis Finansial Jeruk Keprok Di Kabupaten Kutai Timur Di Kabupaten Kutai Timur ( Prospect of Keprok Orange in Kutai Timur Regency ) Dina Lesmana. EPP, $6(1), 36-43$.

Menzel, C. M., Carseldine, M. L., Haydon, G. F., \& Simpson, D. R. (1992). A review of existing and proposed new leaf nutrient standards for lychee. Scientia Horticulturae, 49(1-2), 33-53. https://doi.org/10.1016/0304-4238(92)90141-X

Rahayu, A. (2012). Karakterisasi dan evaluasi aksesi pamelo (Citrus maxima (Burm.) Merr.) berbiji dan tidak berbiji asli Indonesia [vigor kekuatan tumbuh benih jeruk besar (Citrus maxima (Burm.) Merr.) untuk batang bawah] pada kondisi cekaman oksigen rendah. Institut Pertanian Bogor.

Rehman, A., Qamar, R., \& Qamar, J. (2014). Economic Assessment of Sugarcane (Saccharum officinarum L.) through Intercropping. Journal of Agricultural Chemistry and Environment, 03, 24-28. https://doi.org/10.4236/jacen.2014.33b004

Rosmaiti, R., Saputra, I., \& Yusnawati, Y. (2019). Evaluasi Kesesuaian Lahan Untuk Pengembangan Tanaman Jeruk (Citrus, Sp) Di Desa Jambo Labu Kecamatan Birem Bayeun Kabupaten Aceh Timur. Jurnal Ilmiah Pertanian, 16(1), 64-73. https://doi.org/10.31849/jip.v16i1.2430

Srivastava, A. K., Huchche, A. D., Ram, L., \& Singh, S. (2007). Yield prediction in intercropped versus monocropped citrus orchards. Scientia Horticulturae, 114, 67-70. https://doi.org/10.1016/j.scienta.2007.05.005

Sutopo, S. (2014). Dua belas macam unsur esensial yang dibutuhkan oleh tanaman jeruk. Balai Penelitian Tanaman Jeruk Dan Buah Subtropika Badan Penelitian Dan Pengembangan Pertanian. http://balitjestro.litbang.pertanian.go.id/12-macam-unsur-esensial-yangdibutuhkan-oleh-tanaman-jeruk/

Thamrin, M. (2014). Diagnosis Status Hara Menggunakan Jaringan Daun Untuk Menyusun Rekomendasi Pemupukan Pada Tanaman Jeruk Pamelo (Citrus maxima Merr.). Institut Pertanian Bogor.

Vitriyatul, V. (2012). Laporan Pola Tanam. blog. ub.ac.id/ fitafitriya/2012/06/26/laporanpola-tanam/. 